\title{
Assessing and Characterizing the Perception of Soundscape in the Urban Park: A Case Study of Zayed Park, Egypt
}

\author{
Miram Ali, ${ }^{1, *}$ Hisham S. Gabr, ${ }^{2}$ Ayman Hassan Mahmoud ${ }^{3}$ and Dalia Aboubakr ${ }^{3}$
}

\begin{abstract}
With the growing populations and human activities in the cities and urban dwellings, the quality of soundscape of urban park environment needs to be emphasized. Additionally, with the increasing concurrence of city noises, such as traffic noise pollution. Consequently, this study aims to examine the significance of soundscape and investigate soundscape patterns in Zayed park in Egypt. This study has employed quantitative research method; about 37 visitors were conveniently selected to participate in the subjective assessment of soundscape in Zayed central park via questionnaire surveys. The assessment was conducted at four identified points based on the in-situ surveys (IS), recorded sound (RE), and the Audio-Video reality (VR). The results show an inverse relationship between traffic sound sources and the pleasantness of the participants towards sound. Conversely, there is a strong positive correlation between natural sound sources and participants' pleasantness. Similar results were found when comparing outcomes from the questionnaire generated by the on-site soundwalk and the video reality (VR) laboratory test questionnaire. Thus, this study recommends audio-visual simulations for the urban park's soundscape management and planning.
\end{abstract}

Keywords: Soundscape; Urban parks; Perception; Audio-visual interaction; Zayed Park; Egypt.

Received: 22 October 2021; Accepted: 28 November 2021.

Article type: Research article.

\section{Introduction}

For the conceivable history of human existence, humans have perceived the world through hearing and they are depended on sound to express and communicate among them. ${ }^{[1]}$ Despite the long-understood significance of sound to humans, there is an existing discord; growing population accompaniments of urban developments and natural environment destructions have significantly changed the sonic environment, notably an introduction of noise. ${ }^{[2]}$ Scientists, environmentalists, psychologists, and sociologists concur that soundscape architecture offers a remedy to the negative impacts of urban noise. ${ }^{[3]}$ The bitter truth anthropogenic rapid changings is undeniable. ${ }^{[4]}$ Soundscape architecture is inherently related to

1 Department of Architecture, Faculty of Engineering and Information Technology, Onaizah Colleges, Al Qasim 2053, Saudi Arabia.

${ }^{2}$ Department of Architecture, Faculty of Engineering and Material Sciences, The German University in Cairo (GUC), New Cairo, 16482, Egypt.

${ }^{3}$ Department of Architectural Engineering, Faculty of Engineering, Cairo University, Giza, 12612, Egypt.

*Email: eng_miram@live.com (M. Ali) sound. Whether the context is urban or rural, the shaping of the land has far-reaching consequences for the sonic environment. ${ }^{[5]}$ The sonic environment, in turn, influences people's experiences, health, and wellbeing. Metaphor proposed by the Canadian composer Murray Schafer (1994) has shown the relationship between sound and landscape architecture. ${ }^{[6]}$ Drawing on the artistic work of John Cage, Schafer suggested that the everyday sonic environment can be regarded as a major continuously on-going composition where everyone participates. ${ }^{[6]}$

All sounds, whether, created by footsteps on a gravel path, noise from a car engine, or conversations in a café, are the part of such a composition. Urban parks are a proper analogy of a sonic environment for the soundscape. Parks are important to urban life as urban dwellers spend most of their lives and time in environments that are devoid of nature. ${ }^{[3-6]}$ Urban parks are developed to improve the quality of urban life and to serve the various environmental functionalities, yet providing a platform for social interactions for the urban dwellers. Despite the efforts to create urban parks, encroachment and poor planning have been identified to impede the achievement of the objectives for which the parks are creating. ${ }^{[2-5]}$ Heavy traffic around the parks area created noise pollution in the 
parks. ${ }^{[7]}$ It is not certain how the urban park acoustic environment is shaped by such noise sources and pollutions. Urban parks are important for the city and urban dwellers because they are created with a conviction to bring the natural environment closer to the people who live in the cities. ${ }^{[9-11]}$ Parks contribute to offer ecological functions and habitats to wildlife within urban settings; which meets the intrinsic need for nature by humans. ${ }^{[12]}$ In congested cities with limited spaces for face-to-face interactions, urban parks provide the much-needed space for social interactions. ${ }^{[13]}$ Notably, urban dwellers tend to be more attached to urban parks, mostly because of the physical and social space that enables public to interact in a context is perceived as natural. ${ }^{[9]}$ Park is among the places where people will visit with families or in couples spend peaceful time while exercising and healthy games in such environments away from the congestion of the city/urban life. Concisely, acoustic environments that are due to urban parks offer city dwellers a temporary escape from the busy city life; this makes such environments not just the physical existence of space, but also the source for environmental quality, safety, identity, image, vegetation configuration, and quality of life. ${ }^{[10]}$ Urban parks are however cited within marginal lands in the cities and urban areas.

This defines them as buffers between incompatible land use because of the urban encroachments and market mechanisms. ${ }^{[3]}$ Most urban parks are situated closer to highways and traffic, implying proximity to sources of environmental pollutions. This reduces the intended quality for the urban parks. Despite such concerns, there is limited characterisation on the environmental pollution effects of quality life on the natural environment. This study aims to investigate soundscape patterns in urban parks. Specifically, the study seeks to understand how park visitors in Egypt perceive soundscape features and patterns.

\subsection{Soundscape of urban parks}

Urban Park soundscape has an important function of mitigating the impacts of noise pollution in an urban environment ${ }^{[14]}$ refers to this as the auditory refuge role of the soundscape. Given the application of advanced technology for noise control, urban parks may be made free of the noises that emanate from urban traffic and other sources of noise pollution. ${ }^{[9]}$ Additionally, being imitations of the natural environment, urban parks should provide a serene environment that characterises the natural sounds, such as bird sounds and water tumbles. For long, the emphasis in urban parks has been on the visual elements of landscape architecture. ${ }^{[9]}$ With this, the approach adopted in the acoustic environment is for noise control that emphasise the protection of the receiver. ${ }^{[15,16]}$ There is nearly no intention to actively introduce and manage the desired sounds within the urban parks. Study of [17] suggested high levels of greening in the urban parks. Despite such greening levels, satisfaction can be significantly reduced if the parks are characterized by high noise levels. There are no guidelines for harmonizing the auditory and the visual senses during the design stages of a park, and thereafter. ${ }^{[5]}$

Most urban park designs ignore the integration of soundimage balance for the parks. This is not beneficial, because park visitors, while engaging in diverse activities within the parks, also switch to different listening modes, resulting in diverse auditory expectations. ${ }^{[14]}$ The quality of the soundscape in an urban park both directly and indirectly affect different aspects of the park and affect visit decisions to the parks. Usually, the presence of people in the park, which translates to park safety, is considered a pull factor, but this is influenced by the serenity of the park as well. Importantly, the presence of people in the park both acts as informal surveillance to discourage crime, and create an identity for the park. ${ }^{[18]}$ According to [19], natural streams and fountains with several upward jets were preferred water features for promoting relaxation and serenity above waterfalls and fountains with a single upward jet. In terms of interior working environments, it was discovered that people prefer to hear the sound of water, which is $3 \mathrm{~dB}(\mathrm{~A})$ lower than irrelevant speech $48 \mathrm{~dB}(\mathrm{~A})$. The masking impact of the waterscape was also reported to be greater than that of a bird sound. To limit the negative impacts that are induced due to noise, the conservative approaches to noise pollution control attempted to contain the sound intensity. Study of [20] reported that the lower the background level, the quitter it felt. These findings point out the fact that background sounds control is important for evaluating soundscape attributes and enhancing comfort in an acoustic environment. However, other studies have divergent views regarding the recommendation of quietness. Quietness recommendations are not adequate in the design of a desirable acoustic environment. ${ }^{[21]}$ Moreover, study claimed that a pleasant soundscape is never created through elimination of noise alone. Study of [22] revealed that soundscape planning and design is not just about making the environment quite, but the balancing of desirable sound with human needs.

According to Ismail[ ${ }^{[23]}$ preference of higher sound intensities in various environments may be appropriate based on the needs. Concisely, the studies suggest that auditory refugee is not just about a silent environment that is rid of all the noise; but environments that offer desirable and manageable sounds. Thus, Brown ${ }^{[12]}$ asserted that management of sound intensity alone in design of soundscapes may not yield the desired results. Previous research denotes landscape by developing different indicators. ${ }^{[23]}$ Acoustic comfort is one of the important indicators that help with the valuation and the perception of the soundscape. Acoustic comfort is the level of comfort that habitants of a given environment receive from soundscape. Previous studies reported no major differences in acoustic comfort and sound level judgements in ages, gender and ethnicity. ${ }^{[24]}$ Nevertheless, Lercher ${ }^{[20]}$ reported some tendency for teenagers to be most unsatisfied while adults tend to be more satisfied with different soundscape contexts. 
In addition, previous studies reveal differences in sound level evaluations and acoustic comfort evaluations. In such studies, people tend to be more tolerant in acoustic comfort evaluations relative to the sound level evaluations. Regardless of the magnanimity of proposed landscape designs and configurations, the output should not be the focus to practice. This saves on the possibility of the design misinterpretation due to complicated concepts and jargons that shroud clear understanding of the intentions of the designers and planners. $\mathrm{Yu} \&$ Kang ${ }^{[25]}$ proposed acoustic objectives that seek to make communications easy to comprehend. Poor integration of soundscape makes towns and cities dull, with lack of identity. ${ }^{[3]}$ Urban soundscapes that are characterised by high road traffic noise could have clarity and fidelity (hi-fi) attributes.

For instance, natural and human sounds should be predominantly preferred over amplified and mechanical sounds in soundscape integration designs and modification of information content. Emphasis on acoustic objectives enables amendment through community surveys that enable additively for soundscape to meet local aspirations. More significantly, the objectives of soundscape are helpful for music or speech, and enhancing cultural and geographical identity. The design aspects of sound must consider the environmental needs of the sounds. When the sounds that are integrated into a given landscape do not match the context for which they were designed, then they can be negatively rated and considered noise. ${ }^{[25]}$ The physical characteristics of the acoustic environment, the receivers' psychology and needs must be taken into account. ${ }^{[26]}$ Previous studies suggest certain effects and theoretical characteristics of natural sounds and urban noise. ${ }^{[19]}$ Such studies tend to highlight differences between natural sounds in the parks and noise pollution. Nevertheless, the extent to which the environmental and social functions of the urban parks are affected by such noises is little explored. ${ }^{[27]}$ Moreover, there is limited information on the extent to which the acoustic environment can affect the park users' behaviors and perceptions during the visits. Practically, however, limited knowledge in proactive soundscape designs affects the design and implementation measures that are intended to control noise within the parks. ${ }^{[28]}$ Moreover, the management of sounds that contribute to the urban park identities is largely ignored. To enhance urban soundscape roles and their implications to the vibrancy and the health of the urban city dwellers, burgeoning extant reviews suggest a shift from noise control to active soundscape designs.

\subsection{Soundscape and audio video interaction}

The sense of sight, or 'visual,' is critical in the perception of soundscape. Since the introduction of the concept of soundscape, audio-visual interaction has been incorporated into soundscape research, most notably in urban planning and noise control. The study of audio-visual interactions has not only improved and expanded the contents of soundscape assessment, but has also aided in the development of more comprehensive approaches for recording and reproducing audio-visual signals. Interactions between audio and video can have a significant impact on the results of soundscape. ${ }^{[29]}$ This is due to the fact that when aural and visual feelings are combined, paying attention to visual cues changes the conscious perception of sound and vice versa. In the introduction of the soundscape concept, there has been a growing interest in how different combinations of aural and visual scenarios can be used to improve a person's sound perception. A series of in situ assessments and laboratory experiments, ${ }^{[31]}$ investigated the effects of sounds on people's preference for outdoor settings. The importance and impact of this audiovisual interaction work on soundscape perception are still being used today. During this time, the goal of soundscape studies involving audio-visual interactions expanded beyond evaluating traffic noise or urban soundscape. Rather, it had immersed itself in the optimization and design of soundscape.

The evaluating indicators of soundscape assessment involving audio-visual interactions had evolved from a single parameter study to a multiple parameter. Furthermore, as electronic technology advanced, the methods for recording and reproducing audio-visual data for soundscape assessments improved. As a result, in laboratory-based experiments, the spatial sense, immersion, and reduction degree of audio-visual signals have improved.

There is a gap in the systematic investigation of existing publications concerning the assessment and design of soundscapes involving audio-visual interactions. Concisely, there is limited scientific evidence within the Egyptian context to demonstrate the benefits of soundscape designs to urban dwellers, especially within the urban parks. Moreover, there is a need to conduct more studies and publish more literature to support soundscape patterns and designs in Egypt to initiate soundscape-oriented policies

\section{Methodology}

This study adopted quantitative methods and tools including sound walk, questionnaire, acoustics measurements and virtual reality to investigate soundscape patterns in urban parks, and understand how park visitors in Egypt perceive and characterize soundscape features. A quantitative design was preferred for the current study, as it would generate numerical numbers for validation of the outcome.

\subsection{Study area}

The study area was Zayed central park, Egypt. The park was chosen because of its central location in Al sheikh Zayed city. It is located next to several private residential properties, such as the continental gardens and Zed sheikh Zayed Tower. Dense trees and shrubs that encompass the park attract various species of birds and insects. An artificial lacked and water features can be seen in the park. Various natural sounds, such as bird singing, water splashing, and wind can be heard nearly everywhere in the park. Fig. S1 shows the four identified points of study. The most important criteria for the 
identification of the four points as shown in Fig. S1 (named A, $\mathrm{B}, \mathrm{C}$ and $\mathrm{D})$ were based on the proximity to different sound sources, with special emphasis on seating and gatherings areas. Refer to the Fig. S1 (A-B-C-D) for images view

Point (A) is near the main gate and consists of a bridge with interlock tiles flooring overlooking a large artificial lake with a group of fountains. Greenery and roses surround the lake. Point (B) represents a circular place with a group of fixed seats that is semi-shaded by a cloth tent; a group of air-conditioning devices was placed next to the seats with an attempt to isolate them visually with a number of advertising posters. Point (C) is a place for a Catering activity, a large circular food court with a central dancing fountain that is surrounded by a number of restaurant kiosks. The area provides a number of wooden benches facing the fountain, and there is an audio system that plays music continuously. Point (D) is the highest topographically, consisting of a group of wooden benches with large tables. Behind them are stairs leading to a playground.

\subsection{Research design}

Research design and data collection of this study is divided into two steps, an on-site soundwalk and laboratory experiments. This study targeted a population of fifty people, age 20 years and above, male and female visitors who were conveniently selected based on their healthy hearing and understanding of sounds. Eventually, 37 out of the 50 participants completed both on-site soundwalk and the laboratory experiments. Step one, the on-site sound walk was conducted in early March 2021, from 3 to $3.45 \mathrm{pm}$. Participants were asked to stop at the selected location in the park for three minutes and fill in the questionnaire on each targeted point after observing the soundscape.

\subsection{Acoustic measurement}

The soundscape was recorded during the three minutes of stopping at the four points by in-ear binaural microphones. while the acoustical measurements were collected at the same time through the sound level meter Bruel \& Kjaer 2270 with frequency analysis software BZ_72223 that allows real-time frequency measurements in $1 / 1$ and $1 / 3$ octave bands, $1 / 2$ inch microphone type 4189 was used to carry out the measurements, The acoustical calibrator with type 4231(B\&K) was applied to the microphone for checking the calibration of the entire measuring system at $1000 \mathrm{HZ}$. The integration period for each measurement was normalized to three minutes. ${ }^{\left[{ }^{[1]}\right.}$ Equivalent Continuous Sound Pressure Level (LAeq) levels were measured for the four locations. LAeq for point A: 58, LAeq for point B: 67.08 , LAeq for point $C: 68.64$ and for point $D$ was 60.16 .

\subsection{Laboratory data collection}

The laboratory experiment is consisted of two phases, audio and visual recording. Audio and visual data were collected from the 4 evaluated points. Three-dimensional visual data was collected using a spherical panoramic camera (GoPro max
-360 digital action), for 180 seconds at 360 degrees, and with average eye height $1.5 \mathrm{~m}$. The camera and an additional binaural microphone offer full-HD (1080p) video recording for designing audio-visual park environment virtually. The four binaural recorded audio were played for the participants for 3 minutes each. Participants were asked to fill out a questionnaire after listening to each clip. In the experiment's second stage, 360 degrees videos were presented through a VR head mounted display, using the same audio recordings that were recorded binaurally from on-site to experience a virtual soundwalk. Following the watching, participants were required to complete the questionnaire for each location. For all experiments (on-site, recorded only and audio video), the same questionnaire method A (ISO/TS 12913-2:2018) ${ }^{[32]}$ procedure was used. Both on-site and laboratory experiment were employed to investigate the soundscape patterns in Zayed central park, and to examine the key tenets of soundscape in Zayed central park that are considered pleasant and unpleasant.

\subsection{Questionnaire design}

The key aspects of the study, which informed the questionnaire design were sound identification (hearing level), sound sources, sound perception, sound characterization and park visitors' profiles (such as gender and age). The questionnaire comprised of a five-point Likert scale of semi structure questions to understand park visitor's perception of the park, what they hear, and the number of evocations and their perceptions. Likert scale Soundwalk questionnaire was categorized into three (3) steps; Step 1= to rate the level of sound heard/listened by the participant from different sources (Sound identification) where: $1=$ not at all; $2=$ little; $3=$ Moderate, $4=$ high; $5=$ very high. Step $2=$ to rate the perceived sounds based on the 5-point scale where $1=$ very unpleasant, $2=$ unpleasant, $3=$ neither pleasant nor unpleasant, $4=$ pleasant, $5=$ very pleasant. Step $3=$ To describe the general sound environment by list of adjectives as 1 represent the top quality of adjective on the left side and 5 the top of the right-side adjective. The 3 number represent the intermediate value, neither left nor right adjective as shown in Table 1.

Table 1. List of adjective scale for description of sound environment.

\begin{tabular}{llllllc}
\hline Unpleasant & 1 & 2 & 3 & 4 & 5 & Pleasant \\
Unknown & 1 & 2 & 3 & 4 & 5 & Familiar \\
Characteristic & 1 & 2 & 3 & 4 & 5 & Common \\
Discontinuous & 1 & 2 & 3 & 4 & 5 & Continuous \\
Annoying & 1 & 2 & 3 & 4 & 5 & Relaxing \\
Noisy & 1 & 2 & 3 & 4 & 5 & Calm \\
Chaotic & 1 & 2 & 3 & 4 & 5 & Non chaotic \\
Monotonous & 1 & 2 & 3 & 4 & 5 & Vibrant \\
Boring & 1 & 2 & 3 & 4 & 5 & Funny \\
Artificial & 1 & 2 & 3 & 4 & 5 & Natural \\
\hline
\end{tabular}


To further investigate the user perceptions of the park visitors, open-ended questions were included to identify the positive aspects of the park's soundscape, words such as water flow sounds, presence of leaf moves sounds and birds tweets, children's play sound, absence of traffic sound and oriental music were sought for in the responses. The participants reported their level of annoyance with certain dominant sounds in the park, notably, the traffic noise and machine devices. The study also collected demographic data including gender, occupation, age, residency and level of education.

\section{Results}

\subsection{Analysis of sound perception}

Table 2 indicates the findings of perceived/ sound perception as rated by the park visitors and sound characterized based on the sound attractiveness pleasant and unpleasant sound. Aforementioned refer to the (Fig. S1 park map) four points are selected for the data collection in the park and data collection method such as in- situ surveys (IS), recorded studies (RE), and the Audio-Video reality (VR) which is rated by the participants and mean value result is shown in the Table 2 . Sound intensity indicated the level of sound heard by the visitor/respondent at the location and rated from $1=$ not at all to $5=$ extremely high sound intensity. Perception of the sound is indicated by pleasant and unpleasant sound rated by the visitor based on $1=$ very unpleasant and $5=$ very pleasant.

The scores of sound intensity and perception of different sounds were influenced by two main variables; the location/point of data collection and the element of sound. The point of collection determined the proximity from the sources of the sound. For the on-site (IS), recorded and virtual reality data collections. Though point $\mathrm{A}$ is located near the park gate, the average mean value findings indicated that natural sounds intensity $(M=4.21)$; traffic $(M=2.93)$, human sounds $(M=3.03)$ and mechanical sound $(\mathrm{M}=3.15)$ shows that natural sound intensity is relatively higher than other sources produce sound at point $\mathrm{A}$ is shown in Fig. 1a. The perception for traffic sources $(\mathrm{M}=3.55)$, other mechanical sounds $(\mathrm{M}=3.05)$, human sounds $(\mathrm{M}=3.09)$ and natural $(\mathrm{M}=3.79)$ considered significantly high in pleasantness as shown in Fig. $1 \mathrm{~b}$.

Point $\mathrm{B}$ is a seating area beside air conditioning devices. The average mean value findings indicated that traffic sounds intensity $(\mathrm{M}=1.92)$; other mechanical sound $(\mathrm{M}=4.34)$, human sounds $(M=3.07)$ and natural sound $(M=2.95)$ shows that other mechanical sound intensity is relatively higher than other sources produce sound at point B is shown in Fig. 2a. The perception for traffic sources $(\mathrm{M}=4.08)$, other mechanical sounds $(\mathrm{M}=1.29)$, human sounds $(\mathrm{M}=2.83)$ and natural $(M=2.29)$. Since the point is far away from the traffic source visitors rated highest pleasant, in contrary mechanical sound creating very unpleasant perception among the visitors, human and natural sources of sound perception is rated moderate is shown in Fig. 2b.

Point $\mathrm{C}$ has human activities area, with a fountain, and audio system that plays music continuously. The average mean value findings indicated that traffic sounds intensity $(\mathrm{M}=1.34)$; other mechanical sound $(M=4.02)$, human sounds $(M=4.24)$ and natural sound $(\mathrm{M}=4.64)$ shows that natural sound intensity is relatively higher than other sources produce sound at point $\mathrm{C}$, where traffic sound intensity is very low is shown in Fig. $3 a$.

The perception for traffic sources $(M=4.28)$, other mechanical sounds $(M=3.04)$, human sounds $(M=3.55)$ and natural $(M=3.40)$. Since the point is far away from the traffic source visitors rated highest pleasant, in contrary human and natural sound creating unpleasant perception among the

Table 2. Mean Score of three environments for the Soundscape rating by Participants.

\begin{tabular}{|c|c|c|c|c|c|c|c|c|c|}
\hline \multirow[t]{2}{*}{ Location } & \multirow[t]{2}{*}{ Sound Element } & \multicolumn{4}{|c|}{ Sound Level } & \multicolumn{4}{|c|}{ Pleasant/un pleasant } \\
\hline & & IS & $\mathrm{RE}$ & VR & $\begin{array}{l}\text { Mean of three } \\
\text { environments }\end{array}$ & IS & $\mathrm{RE}$ & VR & $\begin{array}{l}\text { Mean of three } \\
\text { environments }\end{array}$ \\
\hline \multirow[t]{4}{*}{ A } & Traffic Sources & 2.78 & 3.27 & 2.76 & 2.93 & 3.51 & 3.49 & 3.65 & 3.55 \\
\hline & Other mechanical sounds & 2.62 & 3.14 & 2.76 & 2.84 & 3.43 & 2.19 & 3.54 & 3.05 \\
\hline & Human Sounds & 2.89 & 3.41 & 2.81 & 3.03 & 3.27 & 2.92 & 3.08 & 3.09 \\
\hline & Natural Sounds & 4.14 & 4.19 & 4.32 & 4.21 & 4.32 & 2.38 & 4.19 & 3.63 \\
\hline \multirow[t]{4}{*}{ B } & Traffic Sources & 2.00 & 1.89 & 1.89 & 1.92 & 3.86 & 4.35 & 4.03 & 4.08 \\
\hline & Other mechanical sounds & 4.08 & 4.54 & 4.41 & 4.34 & 1.38 & 1.27 & 1.24 & 1.29 \\
\hline & Human Sounds & 2.32 & 4.30 & 2.59 & 3.07 & 3.27 & 2.00 & 3.22 & 2.83 \\
\hline & Natural Sounds & 2.76 & 2.14 & 2.68 & 2.52 & 2.38 & 1.76 & 2.57 & 2.23 \\
\hline \multirow[t]{4}{*}{$\mathrm{C}$} & Traffic Sources & 1.43 & 1.22 & 1.38 & 1.34 & 4.08 & 4.43 & 4.35 & 4.27 \\
\hline & Other mechanical sounds & 3.81 & 4.38 & 3.89 & 4.02 & 3.03 & 3.76 & 3.41 & 3.39 \\
\hline & Human Sounds & 4.05 & 4.46 & 4.22 & 4.24 & 3.59 & 3.30 & 3.76 & 3.55 \\
\hline & Natural Sounds & 4.51 & 4.78 & 4.65 & 4.64 & 4.11 & 1.81 & 4.30 & 3.40 \\
\hline \multirow[t]{4}{*}{$\mathrm{D}$} & Traffic Sources & 1.41 & 1.22 & 1.27 & 1.3 & 4.14 & 4.41 & 4.43 & 4.3 \\
\hline & Other mechanical sounds & 2.11 & 1.65 & 1.89 & 1.88 & 2.65 & 4.11 & 4.35 & 3.70 \\
\hline & Human Sounds & 2.11 & 2.51 & 1.95 & 2.19 & 4.11 & 3.41 & 4.16 & 3.89 \\
\hline & Natural Sounds & 4.00 & 4.16 & 4.11 & 4.09 & 4.05 & 3.78 & 4.14 & 3.99 \\
\hline
\end{tabular}

*IS: In site, RE: Recorded soundscape, VR: Audio video recording. 


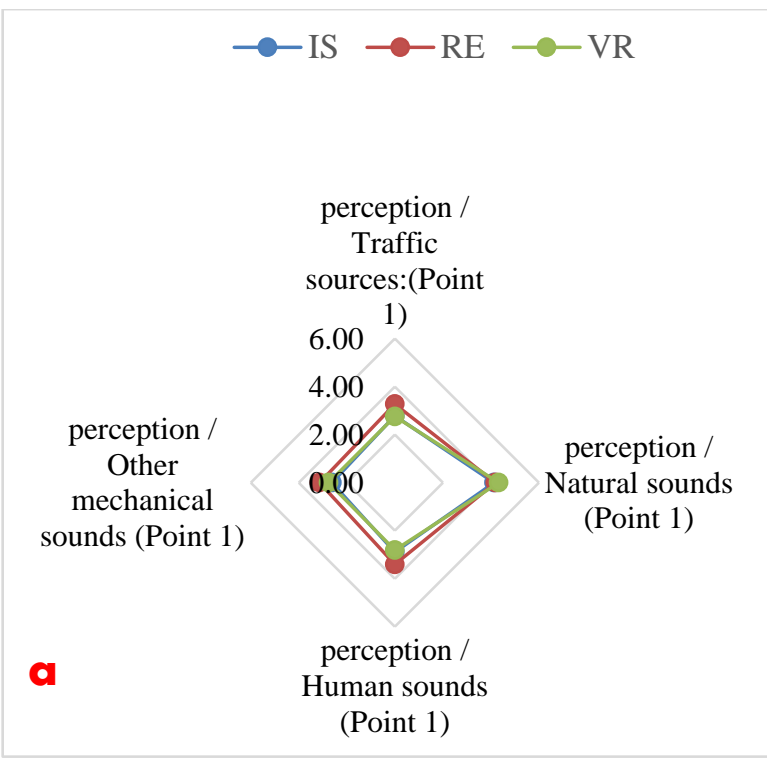

Fig. 1 (a) Point "A" hearing level sources;

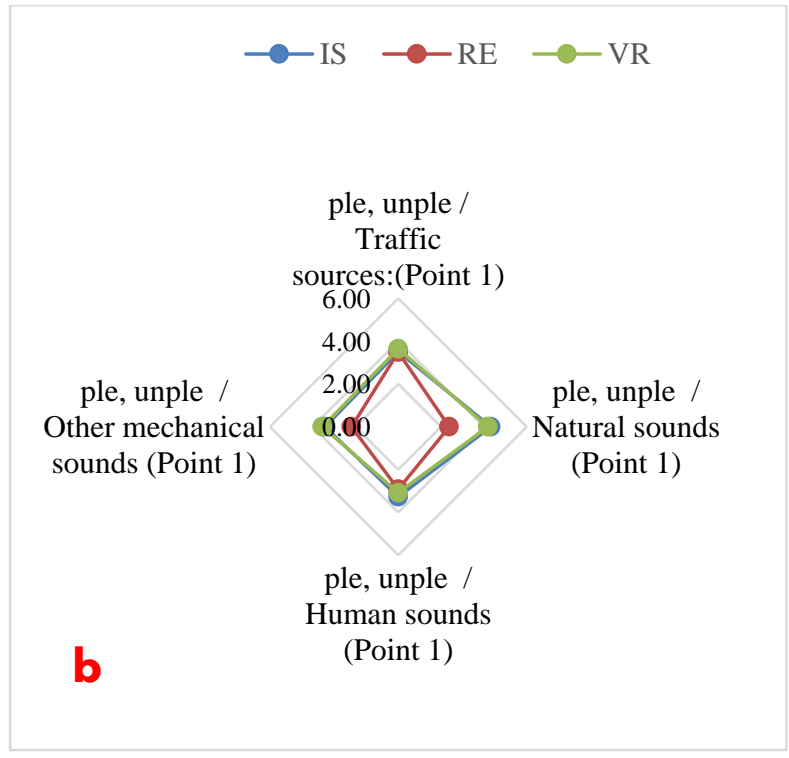

; (b) Sound perceiving in term of pleasure. visitors, mechanical source of sound perception is rated moderate is shown in Fig. 3b.

Point $\mathrm{D}$ is a seating area next to the playground. The average mean value findings indicated that traffic sounds intensity ( $\mathrm{M}=1.30)$; other mechanical sound $(\mathrm{M}=1.88)$, human sounds $(M=2.19)$ and natural sound $(M=4.09)$ shows that natural sound intensity is relatively higher than other sources produce sound at point $\mathrm{D}$, where traffic sound intensity is very low is represented in Fig. 4a. The perception for traffic sources $(\mathrm{M}=4.32)$, other mechanical sounds $(\mathrm{M}=3.70)$, human sounds $(M=3.89)$ and natural $(M=4.01)$. Since the point is far away from the traffic source visitors rated highest pleasant, in contrary human and other mechanical sounds creating unpleasant perception among the visitors, natural sources of sound perception is rated pleasant shown in Fig. $4 \mathrm{~b}$.

\subsection{Characterising the sound environment}

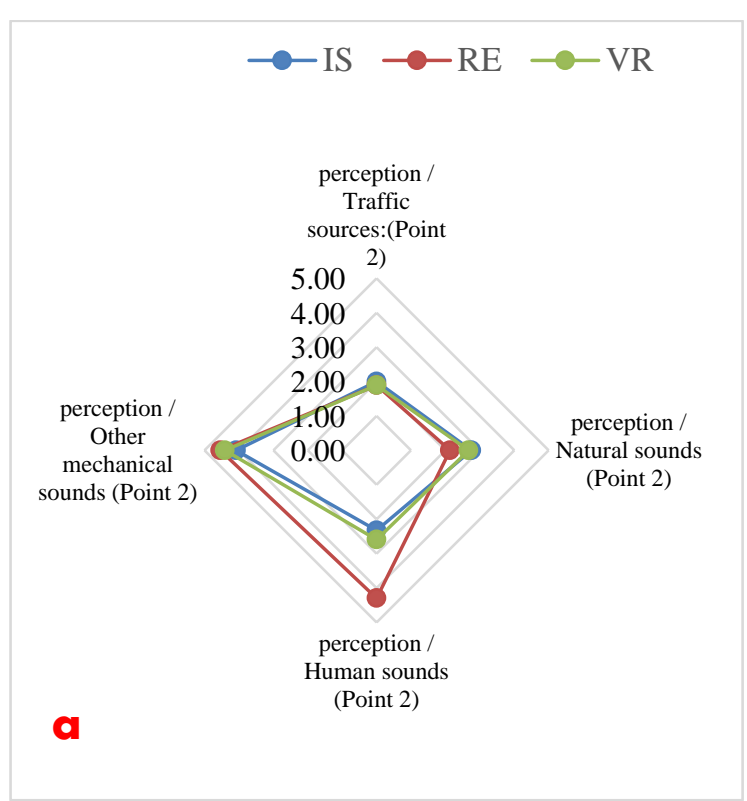

Fig. 2 (a) Point "B" hearing level sources; (b) perceiving of sound in term of pleasure.
The participants were expected to characterise the sound environment using specific adjectives to describe the soundscape. This study presents the summary correlational analysis results after characterising the park environment based on different descriptors; (Fig. S2) shows that, "pleasant/unpleasant, noisy/calm, unknown/familiar, characteristics/common, annoying/relaxing and chaotic/non chaotic" were perceived differently amongst on-site and VR compared with recorded environment. Point B was characterized by many of negative qualities of sound, the participants described it as boring, un pleasant, annoying, chaotic and noisy. (Fig. S3) shows that the ten perceptual attributes were fairly similar within the three environments. While the descriptions of the participants at point $C$ varied to pleasant, Funny, Vibrant, continuous and familiar is shown in Fig. S4). On the contrary, the area has been described as chaotic, noisy, artificial, common and annoying. At point $\mathrm{D}$,

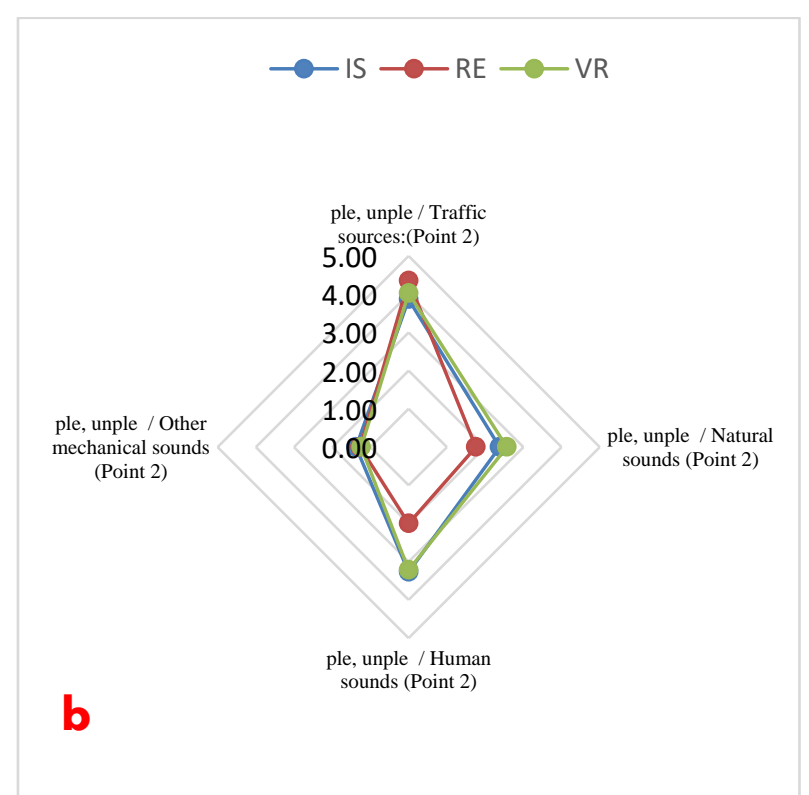




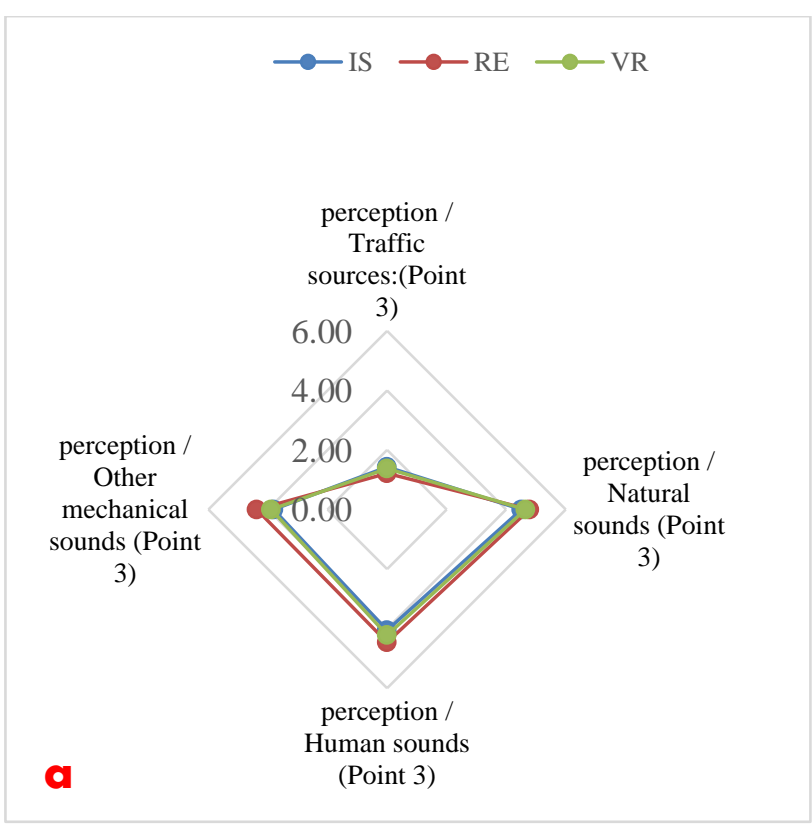

Fig. 3 (a) Point "C" hearing level from sources;

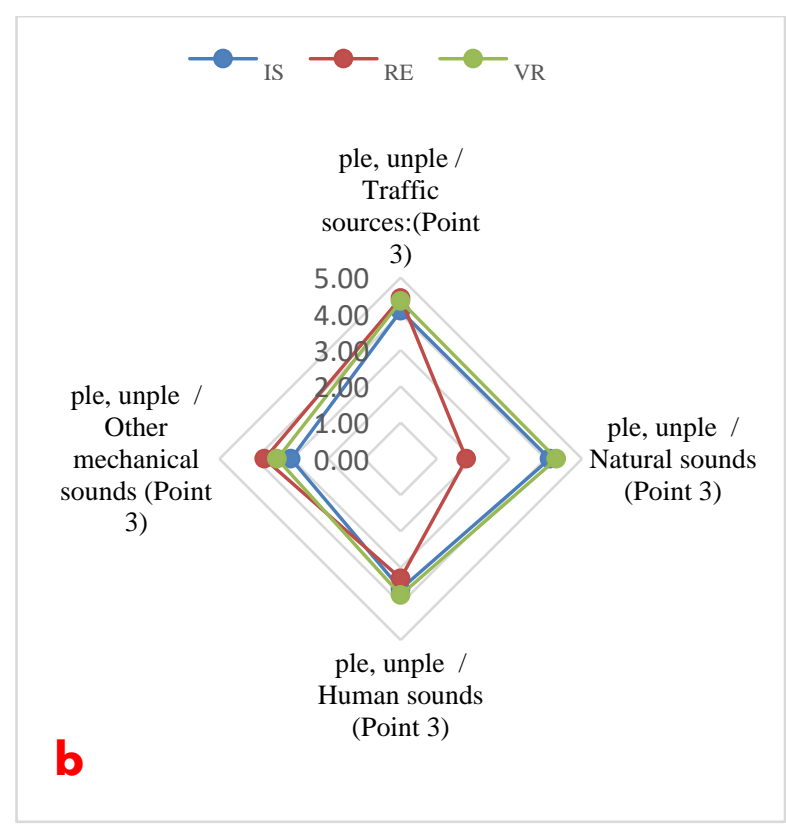

(b) perceiving of sounds in terms of pleasure.
(Fig. S5) shows that "pleasant, artificial, vibrant and annoying" were perceived differently amongst on-site and VR compared with recorded environment. A Pearson's correlation was used to assess the relationship between the mean scores of the onsite, recorded and Virtual reality items for the ten descriptors attributes. The findings show a statically significant and strong positive correlation between on-site environment and virtual reality environment (Table 3 ).

\section{Discussion}

This study finding suggests that recognising a sound source that is accurately produced by an element is a key cue for determining the right sound congruence with the landscape. The findings suggest that individuals have a general tendency to respond to tranquillity in both the acoustic and visual settings from different locations and proximities. The current findings thus emphasise the importance of auditory perception and visual information in landscape appraisal, which is depicted by pleasantness or unpleasantness of a sound source. As in the findings, assessment of the soundscape in complete isolation from the visual may not lead to accurate results. Chitra ${ }^{[27]}$ demonstrated that natural scenery, and not artificial scenery, might generate environmental sound, which influences audio perception. The evaluation of comfort with the audio element at a natural environment is important for determining the level of satisfaction and experience. As in the current study findings, the natural ambient sound features contributed to the pleasantness and preference for and improved impression of the park soundscape setting. This finding agrees with Jo and $\mathrm{Jeon}^{[2]}$ found that soundscape influenced positive landscape assessments, with artificial sounds scoring lower than natural or musical sounds.

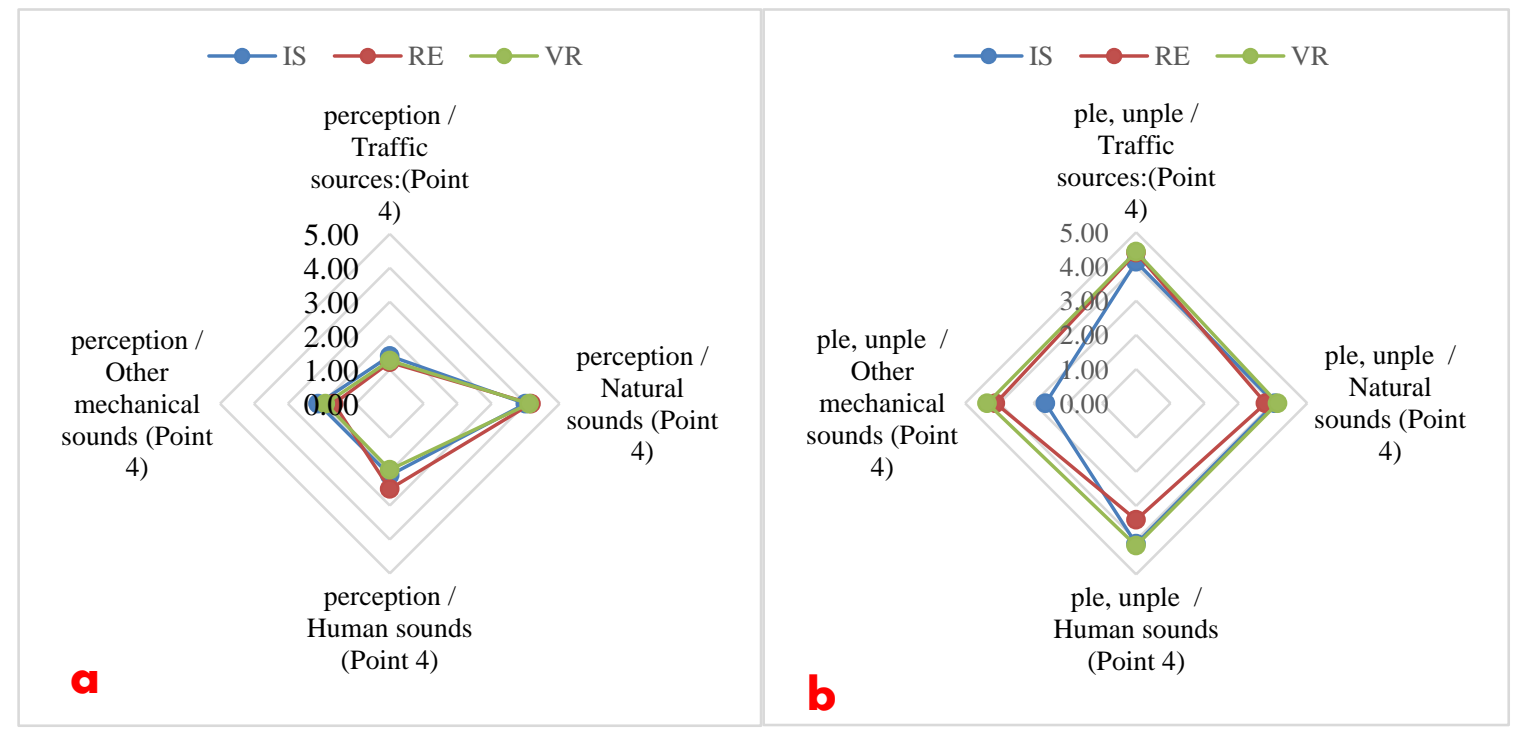

Fig. 4 (a) Point "D" Hearing level from sources; (b) Perceiving of sounds in terms of pleasure. 
Table 3. Correlation between on-site and virtual reality environment.

\begin{tabular}{ccccc}
\hline & & IS & RE & VR \\
\hline \multirow{2}{*}{ IS } & Pearson Correlation & 1 & $.649^{* *}$ & $.929^{* *}$ \\
& Sig. (2-tailed) & & 0.000 & 0.000 \\
RE & Pearson Correlation & $.649^{* *}$ & 1 & $.526^{* *}$ \\
& Sig. (2-tailed) & 0.000 & & 0.001 \\
VR & Pearson Correlation & $.929^{* *}$ & $.526^{* *}$ & 1 \\
& Sig. (2-tailed) & 0.000 & 0.001 & \\
\hline
\end{tabular}

** Correlation is significant at the 0.01 level (2-tailed).

Although natural sounds, such as flow streams and fountains are perceived to improve satisfaction with the park visits, the intensity of the sounds may invoke annoyance and dissatisfaction instead. The sound of a fountain has been demonstrated to cause similar auditory irritation, especially when the noise level of the fountain is 10 to $15 \mathrm{~dB}$ higher than that of road traffic. ${ }^{[19]}$ In contrast, Brooks ${ }^{[3]}$ suggested that adding the sound of stream and lowering the intensity of the original environment could improve the comfort level of the environment. Surprisingly, when respondents were exposed to an audio-visual environment, the perceived loudness of a waterscape was significantly lowered. As a result, when tailored noises are employed to mask environmental noise in points with human activities, the visibility of water may have a greater favourable effect. Concisely, the acoustical properties of water sounds and the visual features of water influence waterscape choices.

High-annoyance sound is frequently associated with road traffic noise, notably from the highway or expressway. In an earlier study by Jeon \& $\mathrm{Jo}^{[2]}$ noise from new highways may have a negative impact on short-term verbal memory and result in an increase in visual and noise discomfort. For the current study, the results show a clear decrease in the participants' hearing of the sound sources generated by traffic at Zayed Central Park. However, the results showed a strong inverse relationship between hearing the sound of traffic sources and the pleasantness of visitors.

Furthermore, behind background scenery, the proximity from other mechanical sounds was one of the most influential factors on the sense of overall pleasantness of the park environment. The visibility of the sound source is both a functional signal of the visual settings and an influencing factor on the aural perception. This is evidenced Point C, where the visual influences the auditory pleasantness. This matched with what $\mathrm{Li}$ and $\mathrm{Lau}^{[19]}$ have suggested that the auditory impressions are influenced by visual factors as well as auditory expectations created by visual information. The effect of source visibility on food court area changed at the recorded environment. If the sound source (whether pleasant or unpleasant) is visible and the sound hearing level is high, noise annoyance rating tend to rise. It is worth noting, that many factors may contribute to influence the soundscape perception, for instance: park size, Park function, fountains and vegetation. At point $\mathrm{A}$, the sound of water splashing was able to mask the low-frequency road traffic noise. It was important to note that identifying the preferred and unfavorable sounds is not enough to consider the acoustic environment positively. This was evident in areas that did not record high rates of unfavorable sounds (point D), whether in self-assessment or through measurements. Despite the area was described by many negative qualities, such as boredom and monotonous.

\section{Conclusion}

This study sought to characterise the soundscape patterns in the urban public open spaces. Specifically, the study explored how park visitors in Zayed park in Egypt perceived soundscape features and patterns. The study used both the insitu and laboratory surveys to examine the soundscape of audio-visual interaction at four selected data collection points in the park. All data from the questionnaire and the sound level metre were analysed and compared. Among the most significant findings, it is worth noting that the area near the main entrance (point 1) had a perceived positive soundscape, despite the presence of noise from the nearby parking plots and road. This is due to the presence of the greenery, fountain and the artificial lake, which enhanced the appearance of natural sounds. Similar conditions took place in vibrant area of the park, the food court area (point 3), where interviews revealed a good perception of the soundscape despite high sound pressure levels.

The study findings, triangulated with the literature that suggest that audio-visual interaction, waterscape, and natural and human sounds are effective factors that influence the acoustical characteristics of the urban park environments. These features in turn influence the pleasantness with the park visits. These findings show how a design approach that takes into account people's perceptions as well as physical parameters can ensure a wide range of positive effects in terms of economics, quality of life, perceptual identity, and better feedback from the community. This study recommends audiovisual simulations for the urban park's soundscape management and planning. Recent technologies such as the use of augmented reality (AR) technology in the design and refurbishment of soundscapes can improve the perception and pleasantness of the park environments.

\section{Conflict of interest}

There are no conflicts to declare. 


\section{Supporting information}

Applicable.

\section{References}

[1] B. Chitra, M. Jain and F.A. Chundel, Environ. Technol. Inno., 2020, 28, 36-41, doi: 10.1016/j.eti.2020.100998.

[2] J. Hi and J. Y. Jeo, Build environ, 2020, 15, 106975, doi: 10.1016/j.buildenv.2020.106975.

[3] B.M. Brooks, B. Schulte, K.S. Voigt and E. A. U. Case., Appl. Acoust., 2014, 10, 30-40, doi: 10.1016/j.apacoust.2011.10.009.

[4] M. Ahmad, S. Beddu, Z. Itam and F. B. Alanimi, Adv. Sci. Technol. Res. J., 2019, 13, 88-109, doi: $10.12913 / 22998624 / 103425$.

[5] J. Kang, Front. Eng. Manag., 2017, 17, 184-92, doi: 10.15302/J-FEM-2017026

[6] A. Soares and J. L. B. Coelho, Noise Mapp., 2016, 3, 232-246, doi: 10.1515/noise-2016-0016.

[7] J. Y. Jeon and J. Hi, Build. Environ., 2020, 1, 106-114, doi: 10.1016/j.buildenv.2019.106544.

[8] B. Givoni, Climate considerations in building and urban design, 1998, John Wiley \& Sons; New York, USA.

[9] A.Chiesura, Landscape urban plan., 2004, 15, 129-138, doi: 10.1016/j.landurbplan.2003.08.003.

[10] J.Y Hong, B. Lam, Z. T. Ong, K. Ooi, W. S.Gan, J. Kang, J. Feng, S. T. Tan, Build. Environ., 2019, 148, 1-14, doi: 10.1016/j.buildenv.2018.12.004.

[11] D. Kim and J. Jin, Landscape Urban Plan., 2018, 178, 1-11, doi: 10.1016/j.landurbplan.2018.05.010.

[12] D. C. Dearborn and S. Kark, Conserv. Biol., 2010, 24, $432-$ 40, doi: 10.1111/j.1523-1739.2009.01328.x.

[13] S. Beddu, M. Ahmad, D. Mohamad, M. I. N. Ameen, Z. Itam, N. L. M. Kamal and N. A. N. Basri, AIMS Mater. Sci., 2020, 7, 911-925, doi: 10.3934/matersci.2020.6.911.

[14] M. Rychtáriková and G. Vermeir, Appl. Acoust., 2013, 74, 240-247, doi: 10.1016/j.apacoust.2011.01.004.

[15] A.L Brown and A. Muhar, J. Environ. Plann. Man., 2004, 1, 827-842, doi: 10.1080/0964056042000284857.

[16] X. H. Song, T. D. Cho and Y. J. Piao, J. Environ. Sci. Inter., 2012, 21, 1053-1058. , doi: 10.5322/JES.2012.21.9.1053.

[17] A.L Brown, Inter. J. Acoust. Vib., 2012, 1, 73-81.doi: 10.1016/j.scitotenv.2012.08.041.

[18] B. Chitra, M. Jain and F. A. Chundelli, Inter. J. Eng. Technol., 2020, 8, 2277-3878, doi:10.35940/ijrte.F7694.038620.

[19] H. Li and S. K Lau, Appl. Acoust., 2020, 166, 107372, doi: 10.1016/j.apacoust.2020.107372.

[20] P. Lercher, Integrating human health into urban and transport planning, 2019, 7, 443-481, doi: 10.1007/978-3-31974983-9 22.

[21] A. Francesco and J Kang, Inter. J. Environ. Res. Public health, 2019, 16, 4988, doi: 10.3390/ijerph16244988.

[22] F. Aletta, J. Kang and O. Axelsson, Landscape Urban Plan., 2016, 1, 65-74, doi: 10.1016/j.landurbplan.2016.02.001.

[23] M. R. Ismail, Front. Archit. Res., 2014, 3, 55-68, doi: 10.1016/j.foar.2013.10.002.

[24] A. Gramez and F. Boubenider, Appl. Acoust., 2017, 1, 39-49, doi: 10.1016/j.apacoust.2016.11.014.

[25] C. J. Yu and J. Kang, Sci. Total Environ., 2014, 482, 501-509, doi: 10.1016/j.scitotenv.2013.10.107.

[26] A. Eleinen, G. Elrayies, R. Hussein, Port-Said Eng. Res. J., 2016, 20, 10-6, doi:10.21608/PSERJ.2016.33572.

[27] B. Chitra, M. Jain, F.A. Chundelli, Environ Technol. Inno., 2020, 19, 100998, doi: 10.1016/j.eti.2020.100998.

[28] F. Aletta and J. Kang, Noise Mapp., 2015, 2, 1-12, doi: 10.1515/noise-2015-0001.

[29] M. Lindquist. PhD diss. 2014. University of Sheffield. https://etheses.whiterose.ac.uk/6675/.

[30] L. M. Anderson, B. E. Mulligan, L. S. Goodman, H. Z. Regen, Environ. Behav., 1983, 15, 539-66, doi: 10.1177/0013916583155001.

[31] B. Szeremeta and P.H Zannin, Sci. Total Environ., 2009, 407, 6143-6149, doi: 10.1016/j.scitotenv.2009.08.039.

[32] International Organization for Standardization, 2018, ISO/TS 12913-2:2018 Acoustics — Soundscape — Part 2: Data collection and reporting requirements. Geneva: ISO.

[33] O. Axelsson, M. E. Nilsson and B. Berglund, J. Vision., 2010, 128, 2836-2834, doi: 10.1167/13.5.3.

\section{Author Information}

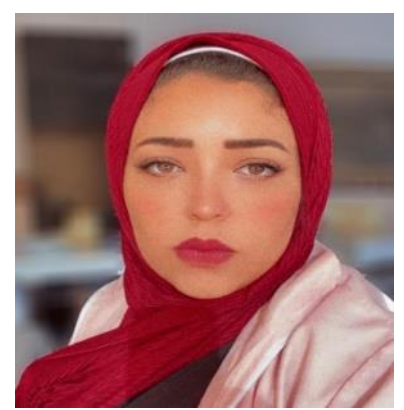

Miram Ali, is an Architect, researcher and lecturer at the Department of Architecture, Faculty of Engineering and Information TechnologyOnaizah Colleges, Saudi Arabia. She obtained completed master degree in Architectural studies from Cairo University Faculty of engineering, architecture department. Currently she is pursuing PhD in Assessing and characterizing the soundscape in urban parks. Her research interests in acoustics design and assessment of indoor and outdoor soundscape environments. She involved in several research projects relating soundscape and acoustics architectural design. 


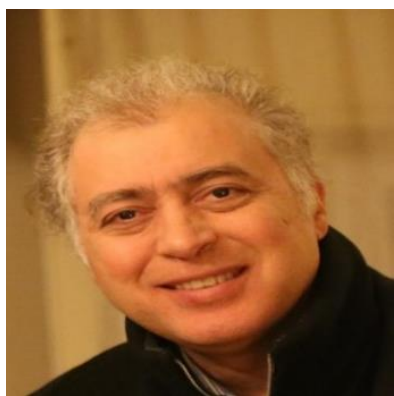

Hisham S. Gabr is a professor of architecture in the Department of Architecture, Faculty of Engineering and Materials Sciences, the German University in Cairo with 39 years of teaching and research mostly in the Department of Architecture, College of Engineering, Cairo University and other institutions. Prof. Gabr has a PhD from the University of Wisconsin, Milwaukee, USA (1993) in Environment Behavior Studies (EBS) which investigates the relationships between humans and architecture (built \& natural environments). He earned his BSc and MSc degrees from Cairo University, 1982 \& 1988 respectively. His research interests and experiences has covered several specialized areas under the broad studies of the interrelationships between human behavior and architecture. Specific research interests included tourism and waterfront development, cultural and heritage issues, architectural aesthetics, post occupancy evaluation, and innovative aspects in design.

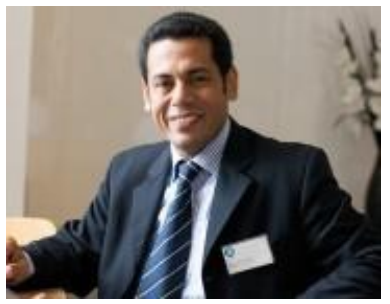

Ayman Hassan Mahmoud is a professor of Landscape Architecture, He is currently the head of Architecture department at College of Engineering, Cairo University. His research interests lie in the area of landscape design, outdoor spaces, environmental planning and thermal comfort.

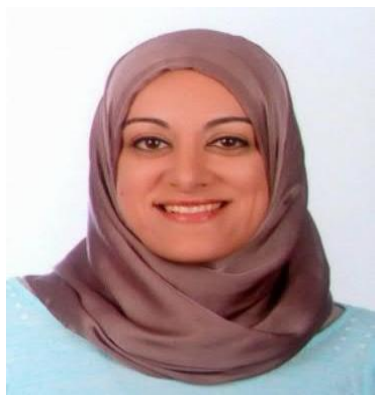

Dalia AbouBakr, architect, researcher and Assistant Professor at the Department of Architecture, Faculty of Engineering - Cairo University, Egypt. Her PhD in Architectural Studies was awarded by Cairo University in 2016, under the Title: "A Geometric Approach Towards Biophilic Design." Her MSc was awarded by Cairo University, in 2011. She is interested in the research of architecture education, design pedagogy, design methods, biophilia/biophilic design, and neuroscience architecture.

Publisher's Note: Engineered Science Publisher remains neutral with regard to jurisdictional claims in published maps and institutional affiliations. 